\title{
Parametric Appraisal of Process Parameters for Adhesion of Plasma Sprayed Nanostructured YSZ Coatings Using Taguchi Experimental Design
}

\author{
Sisir Mantry, ${ }^{1}$ Barada K. Mishra, ${ }^{1}$ and Madhusudan Chakraborty ${ }^{2}$ \\ ${ }^{1}$ CSIR-Institute of Minerals \& Materials Technology, Bhubaneswar 751013, Odisha, India \\ ${ }^{2}$ Indian Institute of Technology Bhubaneswar, Bhubaneswar 751007, Odisha, India \\ Correspondence should be addressed to Sisir Mantry; mantrysisir@gmail.com
}

Received 26 August 2013; Accepted 15 September 2013

Academic Editors: V. Calderón, W. Li, and K. Prabhakaran

Copyright ( $\odot 2013$ Sisir Mantry et al. This is an open access article distributed under the Creative Commons Attribution License, which permits unrestricted use, distribution, and reproduction in any medium, provided the original work is properly cited.

This paper presents the application of the Taguchi experimental design in developing nanostructured yittria stabilized zirconia (YSZ) coatings by plasma spraying process. This paper depicts dependence of adhesion strength of as-sprayed nanostructured YSZ coatings on various process parameters, and effect of those process parameters on performance output has been studied using Taguchi's $\mathrm{L}_{16}$ orthogonal array design. Particle velocities prior to impacting the substrate, stand-off-distance, and particle temperature are found to be the most significant parameter affecting the bond strength. To achieve retention of nanostructure, molten state of nanoagglomerates (temperature and velocity) has been monitored using particle diagnostics tool. Maximum adhesion strength of $40.56 \mathrm{MPa}$ has been experimentally found out by selecting optimum levels of selected factors. The enhanced bond strength of nano-YSZ coating may be attributed to higher interfacial toughness due to cracks being interrupted by adherent nanozones.

\section{Introduction}

Increased operating temperatures and hence improved performance of gas turbines or diesel engines can be realized by using thermal barrier coatings (TBC) [1-6]. Plasma sprayed thermal barrier coatings based on yttrium stabilized zirconia (YSZ) have been applied to hot section components. Zirconium based ceramics are considered to be best suitable for thermal barrier and wear resistance application due to its low density, high hardness, and low thermal conductivity. YSZ is the current industrial standard material of TBCs, owing to its low thermal conductivity, phase stability at relatively high temperatures, a relatively high coefficient of thermal expansion (CTE), and chemical inertness in combustion atmospheres as compared to other ceramics [7-11].

The advantages of plasma spraying include formation of ceramic microstructures with fine, equiaxed grains without columnar defects, deposition of graded coatings with a wide compositional variety, formation of thick coatings with only modest investment in capital equipment, and design capability for free standing thick forms of monolithic and mixed ceramics in near net shape configuration. Plasma spray coating is a typical thermal spraying process that combines particle melting, quenching, and consolidation in a single operation. It utilizes the exotic properties of the plasma medium to process different materials.

YSZ coating has been proved to be more resistant against wear compared with other ceramic coatings. The higher wear resistance of the nanostructured coatings is attributed to their optimized microstructure and improved microhardness [12]. In recent years, there has been a growing interest in manufacturing and deposition of nanoscale powders. Bulk nanostructured material (grain size $<100 \mathrm{~nm}$ ) has exhibited outstanding mechanical properties such as exceptional hardness, yield strength, and wear resistance [13-15]. Thermal spray coatings obtained from nanostructured powders (as shown in Figure 1) also exhibit such outstanding properties. Exceptional properties can be obtained if nanostructure of feedstock can be preserved during spraying and retained in the coating microstructure. Plasma spraying is a technique suited 


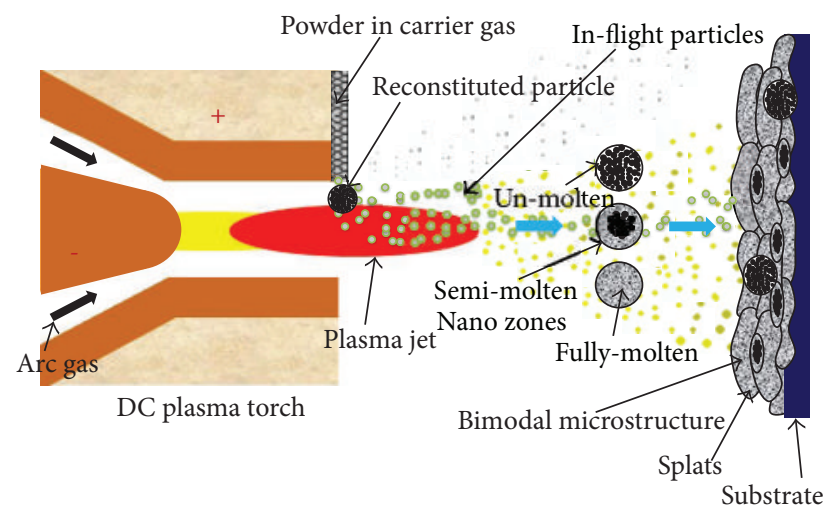

FIGURE 1: Schematic diagram of plasma spray coating process using nanostructured agglomerates.

for this application because of short dwell time of powders at high temperature. However, process parameters must be carefully optimized to avoid grain coarsening and phase stability of materials [16].

Studies related to identification and quantification of phase transformations in plasma sprayed YSZ coatings have been done [17-19]. These characteristics are helpful in predicting the coating behavior under controllable plasma spray processes but are not sufficient in finding the means of a systematically optimal coating. In thermal barrier coating processes, appropriate use of modeling of a process model is rare. Detailed analysis of the relationship between independent variables and responses has not been established yet. Further, the impacts and importance of plasma spraying process factors on the surface coatings are still not well understood. The choice of parameters needs some understanding of the process as there are as many as 50 process variables [20]. To improve adhesion, all process parameters need to be understood, so as to undertake appropriate steps in the design of substrates and coating materials [21]. As the number of such process parameters is too large, statistical techniques could be employed for identification of significant process parameters for optimization. In this context, Taguchi experimental design offers an excellent tool for optimizing the total cost without compromising the performance output. In this work, this method has been adopted to investigate the influencing parameters like torch input power, molten particle velocity, stand-off distance, and powder feed rate on the adhesion strength of splat-substrate interface.

\section{Experimental Details}

2.1. Synthesis of Nanostructured Powders by Sol-Gel Route. The nanostructured YSZ powders employed in this study were synthesized through sol-gel technique [22]. A water based solution of zirconium oxychloride and yttrium oxide was prepared in order to get $8 \mathrm{~mol} \%$ yttria stabilised zirconia (YSZ). Precursor materials were taken according to the proper stoichiometric, and an excess amount of nitric acid was added to the solution. Final solution was homogenized by constant stirring at $100-120^{\circ} \mathrm{C}$ temprature. After $5-6 \mathrm{~h}$ of constant stirring and heating, the translucent solution (with little amount of citric acid) was heated on a hot plate (at about $200 \pm 250^{\circ} \mathrm{C}$ ) until it turned into a black viscous gel, which on continued heating burned due to a vigorous exothermic reaction. Black ashes obtained after combustion were treated at $350^{\circ} \mathrm{C}$ in air for $1 \mathrm{~h}$ to eliminate the carbonaceous residues and calcined at $600^{\circ} \mathrm{C}$ for $2 \mathrm{~h}$ resulting in YSZ powder.

XRD pattern of synthesized powder, as shown in Figure 2, reveals that the powder is composed of tetragonal zirconia phase $(\mathrm{t}-\mathrm{ZrO} 2)$. TEM image shows that the grain sizes of nanoparticles are between 20 and $30 \mathrm{~nm}$.

2.2. Coating Material. The synthesized powders were then reconstituted to form micrometer-size agglomerates (40$70 \mu \mathrm{m}$ ) that are large enough to be used as commercial powder feeders. The reconstitution process is done through spray drying [23]. The agglomeration of nano-YSZ was carried out in a Buchi B-290 research model spray dryer. A suspension of the nanoparticles was prepared using $300 \mathrm{~mL}$ of deionized $\mathrm{H}_{2} \mathrm{O}, 7 \mathrm{~g}$ of polyethylene glycol (PEG), and $70 \mathrm{~g}$ of nanoYSZ. The polymeric binder, PEG, in solution uses Vander Waals forces to bind the nanoparticles together and forms spherical droplets during atomization. The nano-YSZ slurry was attained via vigorous magnetic stirring for $30 \mathrm{~min}$ and heating to $300 \mathrm{~K}$. The preheating of the solution assists in the slurry formation and in lowering the enthalpy needed during the drying process for moisture removal. The final product is a feedstock of size $\sim 50 \mu \mathrm{m}$ spherical agglomerates containing nanograins of size $20-30 \mathrm{~nm}$ as shown in Figure 3.

\section{Materials and Methods}

The most important step in plasma spray coating technique is the preparation of the substrate surface in order to increase the mechanical anchoring between the substrate and the coating. The surface of the substrate was subjected to grit blasting to make the surface rough. In this grit blasting method, highly compressed air carrying alumina particles were bombarded on the surface to remove some material which made the surface rough. A uniform roughness of 6$8 \mu \mathrm{m}$ was maintained in order to provide better adhesion at the interface. 


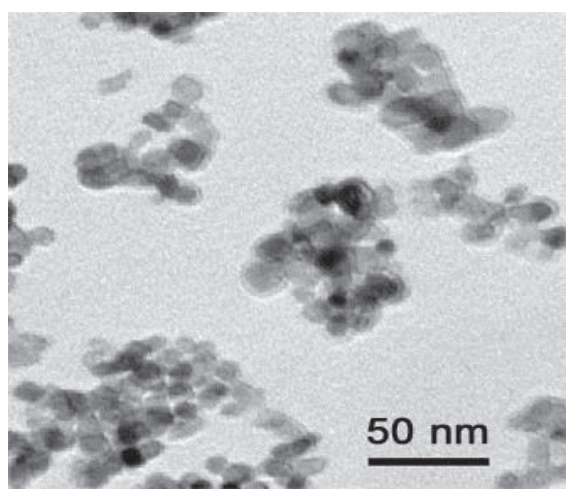

(a)

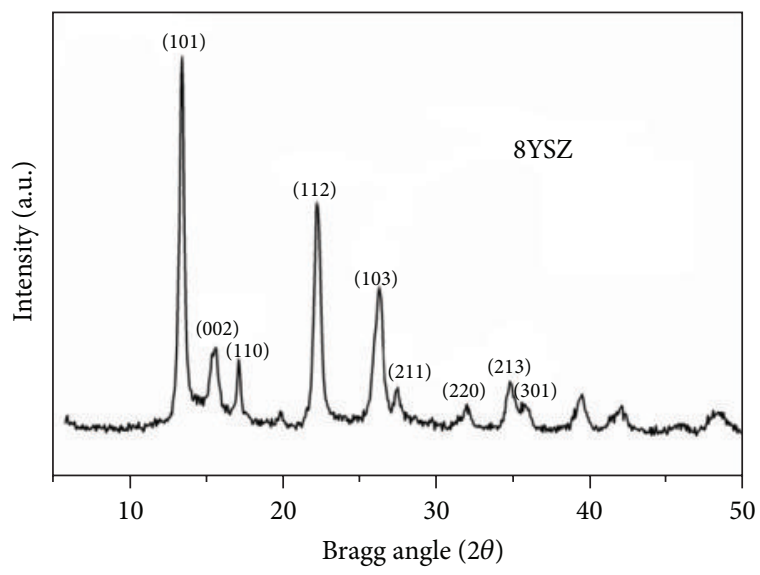

(b)

FIGURE 2: TEM micrograph and XRD pattern of as-synthesized YSZ particles.

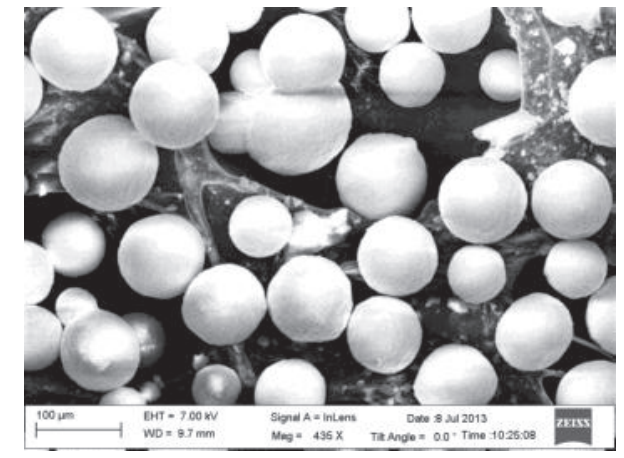

FIGURE 3: FESEM micrograph of spray dried YSZ particles.

The coating process was carried out using an $80 \mathrm{~kW}$ plasma spray system supplied by $\mathrm{M} / \mathrm{s}$ Metallization, UK. This is a typical atmospheric plasma spray system working in the nontransferred arc mode. The setup assembles a number of sub units like a plasma torch mounted on a six-axis robot, power supply (maximum power of $80 \mathrm{~kW}$ ), powder feeders, mass flow controller, plasmagen gas supply, water chiller, and rotating turn table for sample rotation. The entire assembly is housed inside an acoustic chamber and is operated by a control console. In this study, high pure argon and helium were used as primary and secondary plasmagen gases, respectively, at an outlet pressure of $4 \mathrm{~kg} / \mathrm{cm}^{2}$. A roughened Inconel 718 substrate of dimension $120 \times 60 \times 5 \mathrm{~mm}^{3}$ was fixed on the turn table, and YSZ agglomerates were sprayed at different torch input power levels. The process parameters are listed in Table 1. The number of passes was kept constant for each sample in order to make thickness of all coatings within similar range.

3.1. Adhesion Test. To evaluate the coating adhesion strength, universal testing machine (make: INSTRON 8801) is used. The test is conducted by the pullout method as per ASTM C633 standard, as shown in Figure 4, in which two cylindrical
TABLE 1: Selected operating parameters for plasma spray coating process.

\begin{tabular}{lc}
\hline Parameter & Operating range \\
\hline Operating power & $30-45 \mathrm{~kW}$ \\
Current & $500-700 \mathrm{Amps}$. \\
Primary plasmagen gas (argon) flow rate & $45-60 \mathrm{Lpm}$ \\
Secondary plasmagen gas (helium) flow rate & $5-15 \mathrm{Lpm}$ \\
Nozzle to substrate distance (stand-off distance) & $75-150 \mathrm{~mm}$ \\
Powder feed rate & $25 \mathrm{gm} / \mathrm{min}$ \\
\hline
\end{tabular}

specimens are taken. The face of one of the cylinders is coated by plasma spraying with the material under investigation. This coated face is glued with a resin HTK Ultra Bond 100 to the face of the other uncoated cylindrical specimen and kept in furnace at $150^{\circ} \mathrm{C}$ for approximately 1.5 hours for the setting of the glue. This uncoated face is to be sand blasted prior to the gluing. The assembly of the two cylinders is then subjected to gradual tensile load. The cross head speed was kept constant at $1 \mathrm{~mm} / \mathrm{min}$. The tensile strength, that is, the coating adhesion strength is calculated from the division of 


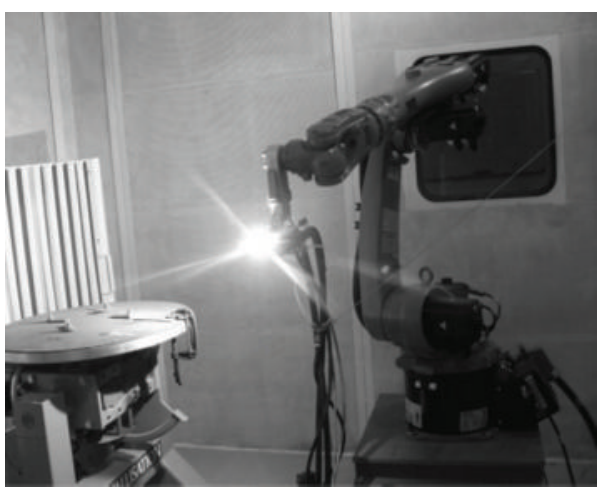

(a)

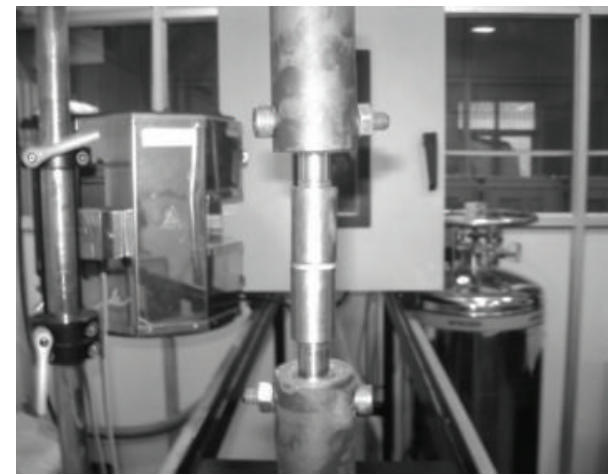

(b)

FIgURE 4: Plasma spraying torch and adhesion test setup as per ASTM C-633 standard.

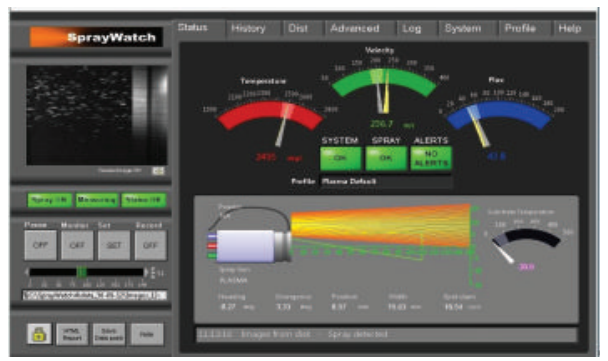

FIgURE 5: Particle velocity and temperature profile by CCD camera.

the maximum load applied at the rupture (i.e., failure occurs only at the coating-substrate interface) by the cross-sectional area of the cylindrical specimen considered.

Coating adherence tests have been carried out by many investigators with various coatings. However, it has been stated that the fracture mode is adhesive if it takes place at the coating substrate interface and that the measured adhesion value is the value of practical adhesion, which later is strictly an interface property, depending exclusively on the surface characteristics of the adhering phase and the substrate surface conditions. Taguchi experimental design is used to identify the most significant parameter affecting adhesion.

3.2. Online Particle Diagnostics. The coating properties are intimately linked to the properties of these lamellae, which in turn depend on inflight particle properties as well as substrate temperature during spraying. It is known that both performance and properties of coatings are influenced largely by the microstructure, which in turn is influenced by the particle state along with substrate and deposition conditions. Online diagnostics as shown in Figure 5 using Spray watch 2i equipment were carried out at different spray conditions to measure the particle velocity and temperature. Distance of the camera from the spray gun was equal to stand-off distance during coating manufacturing being 150 and $200 \mathrm{~mm}$. Particle temperature determination is based on the two-color pyrometry, and in-flight particle velocities are measured from the length of the particle traces during known exposure times using a single high speed CCD camera [24].

3.3. Taguchi Experimental Design. In order to minimize effort and time required for testing without compromising the quality of a product or process, statistical methods are commonly followed [25]. Using these methods, the effect of every single condition in an experiment can be easily defined and studied. In the plasma spray coating process, the desired output, that is, the adhesion strength is dependent on many input factors. In order to study the influence of such factors on the performance output, the Taguchi experimental design is one of the best analysis tools. Using this design, the most significant factor out of large number of factors can be easily identified. It is a powerful analysis tool for modeling and analyzing the influence of control factors on performance output. The most important stage in the design of experiment lies in the selection of the control factors. Therefore, a large number of factors are initially included so that nonsignificant variables can be identified at the earliest opportunity. A literature review on the adhesion of plasma sprayed coatings revealed that parameters such as torch input power, particle velocity, powder feed rate, stand-off distance, and particle size largely influence the adhesion strength [26]. Splat formation depends on the impacting droplet velocity, size, molten state, impact angle, substrate roughness, and temperature [27]. 


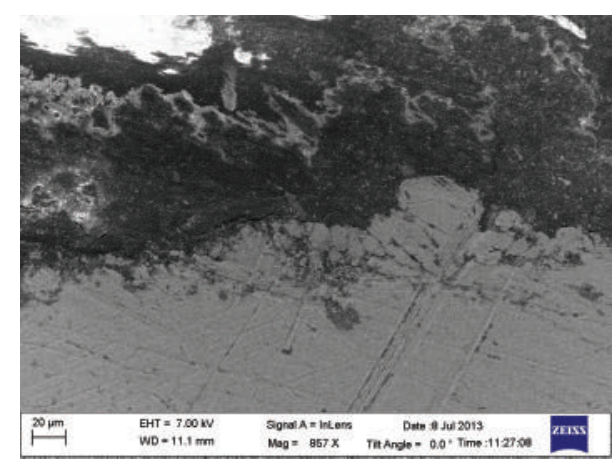

(a)

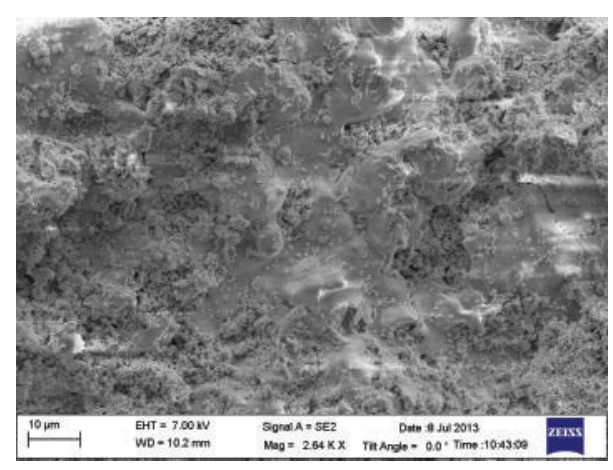

(b)

FIGURE 6: FESEM micrograph of as-sprayed nanostructured coating: (a) cross section, (b) surface.

TABLE 2: Control factors with their selected levels.

\begin{tabular}{|c|c|c|c|c|c|}
\hline \multirow[b]{2}{*}{ A: Torch input power } & \multicolumn{4}{|c|}{ Levels } & \multirow{2}{*}{$\begin{array}{l}\text { Unit } \\
\mathrm{kW}\end{array}$} \\
\hline & 30 & 35 & 40 & 45 & \\
\hline B: Torch to base distance & 75 & 100 & 125 & 150 & $\mathrm{~mm}$ \\
\hline C: Molten particle velocity & 200 & 225 & 250 & 275 & $\mathrm{~m} / \mathrm{sec}$ \\
\hline D: Particle temperature & 2500 & 2600 & 2700 & 2800 & ${ }^{\circ} \mathrm{C}$ \\
\hline E: Surface roughness & 4 & 5 & 6 & 7 & $\mu \mathrm{m}$ \\
\hline
\end{tabular}

The influence of these five factors with their four different levels on the adhesion strength of the coated sample is studied using $\mathrm{L}_{16}$ orthogonal array design. The control factors with their selected levels are shown in Table 2. The output result is further transforms into the signal-to-noise $(\mathrm{S} / \mathrm{N})$ ratios. Since the maximum adhesion is taken into consideration, $\mathrm{S} / \mathrm{N}$ ratios are calculated for maximum under "larger is better" characteristics as a logarithmic transformation of loss function is given below.

"Larger the better" characteristic:

$$
\frac{S}{N}=-10 \log \frac{1}{n}\left(\sum \frac{1}{y^{2}}\right)
$$

\section{Results and Discussion}

Thickness of the nano-YSZ coatings on Inconel substrates is measured on the polished cross sections of the samples, using an optical microscope. Five readings are taken on each specimen, and the average value is reported as the mean coating thickness. The mean coating thickness is found to be $315 \mu \mathrm{m}$.

4.1. Surface Morphology. Figure shows the surface morphology of the as-sprayed nanostructured YSZ coating obtained from field emission scanning electron microscopy (FESEM). Two different surface morphologies are observed. One is the dense and smooth zones, indicating good molten state of particles; the other one is the rough and porous zones, indicating unmolten or semimolten state of particles. The morphology of the cross section of the coating is shown in Figure 6. Splat boundaries of the molten and semimolten particles can be easily distinguished, which indicates that the powder was spheroidized during interaction with the plasma plume. After impingement on the substrate, molten particles form splats and solidify. The morphology of coatings reveals some regions of fully molten ceramic particles along with small pores. Particle distribution seemed to be uniform along the coating surface.

4.2. Adhesion Analysis Using Taguchi Experimental Design. The test results for the adhesion of the nano-YSZ coated substrate according to an $\mathrm{L}_{16}$ orthogonal design along with the corresponding $\mathrm{S} / \mathrm{N}$ ratios are shown in Table 3. All five control factors are represented in second to sixth columns of the table, and the test results (i.e., adhesion strength) are presented in the seventh column. The adhesion test result for each run was the average of the experimental values obtained from three test runs. The $\mathrm{S} / \mathrm{N}$ ratio for each test run was calculated and is shown in last column of Table 3. The overall mean value of the $\mathrm{S} / \mathrm{N}$ ratios for the test run was $30.611 \mathrm{~dB}$. The analysis was made using MINITAB14 software (CSIR-IMMT, Bhubaneswar, India), which is specifically used for design of experiment applications. The response table for the $\mathrm{S} / \mathrm{N}$ ratio using the larger is better characteristics is shown in Table 4 . In this table the delta value of the individual control factor based on the $\mathrm{S} / \mathrm{N}$ ratio is shown, and a rank was accordingly assigned that indicates the significance of the control factors on the performance output. In this study, the molten particle velocity, with a higher delta value, was found to be the most significant factor, followed by the stand-off distance and particle temperature, influencing the adhesion of the interface of nano-YSZ coatings. Figure 7 shows the main effect plot for $\mathrm{S} / \mathrm{N}$ ratios of individual control factors. From the graphical analysis of this figure, it was concluded that maximum adhesion could be obtained with the combination of A3, B3, C1, D2, and E4, which is found to be $40.56 \mathrm{MPa}$. The higher bond strength achieved may be attributed to higher interfacial toughness due to cracks being interrupted by strong adherent nano-zones [28].

\section{Conclusion}

This experimental and analytical investigation on the nanostructured YSZ coated Inconel 718 substrate leads to the following important conclusions. 
TABLE 3: $\mathrm{L}_{16}$ Orthogonal array design with output and $\mathrm{S} / \mathrm{N}$ ratio.

\begin{tabular}{|c|c|c|c|c|c|c|c|}
\hline Test run & $\begin{array}{l}\text { Torch input } \\
\text { power }(\mathrm{kW})\end{array}$ & $\begin{array}{c}\text { Particle } \\
\text { temperature } \\
\left({ }^{\circ} \mathrm{C}\right)\end{array}$ & $\begin{array}{l}\text { Particle velocity } \\
\qquad(\mathrm{m} / \mathrm{sec})\end{array}$ & $\begin{array}{l}\text { Substrate } \\
\text { roughness }(\mu \mathrm{m})\end{array}$ & $\mathrm{SOD}(\mathrm{mm})$ & $\begin{array}{c}\text { Adhesion } \\
\text { strength (MPa) }\end{array}$ & $\mathrm{S} / \mathrm{N}$ ratio \\
\hline 1 & 30 & 2500 & 200 & 4 & 75 & 30.39 & 29.6546 \\
\hline 2 & 30 & 2600 & 225 & 5 & 100 & 36.67 & 31.2862 \\
\hline 3 & 30 & 2700 & 250 & 6 & 125 & 32.89 & 30.3413 \\
\hline 4 & 30 & 2800 & 275 & 7 & 150 & 29.45 & 29.3817 \\
\hline 5 & 35 & 2500 & 275 & 6 & 100 & 28.72 & 29.1637 \\
\hline 6 & 35 & 2600 & 250 & 7 & 75 & 38.75 & 31.7654 \\
\hline 7 & 35 & 2700 & 225 & 4 & 150 & 35.29 & 30.9530 \\
\hline 8 & 35 & 2800 & 200 & 5 & 125 & 37.12 & 31.3922 \\
\hline 9 & 40 & 2500 & 225 & 7 & 125 & 38.71 & 31.7565 \\
\hline 10 & 40 & 2600 & 200 & 6 & 150 & 39.37 & 31.9033 \\
\hline 11 & 40 & 2700 & 275 & 5 & 75 & 33.90 & 30.6040 \\
\hline 12 & 40 & 2800 & 250 & 4 & 100 & 31.59 & 29.9910 \\
\hline 13 & 45 & 2500 & 250 & 5 & 150 & 34.79 & 30.8291 \\
\hline 14 & 45 & 2600 & 275 & 4 & 125 & 30.43 & 29.6660 \\
\hline 15 & 45 & 2700 & 200 & 7 & 100 & 38.49 & 31.7070 \\
\hline 16 & 45 & 2800 & 225 & 6 & 75 & 29.50 & 29.3964 \\
\hline
\end{tabular}
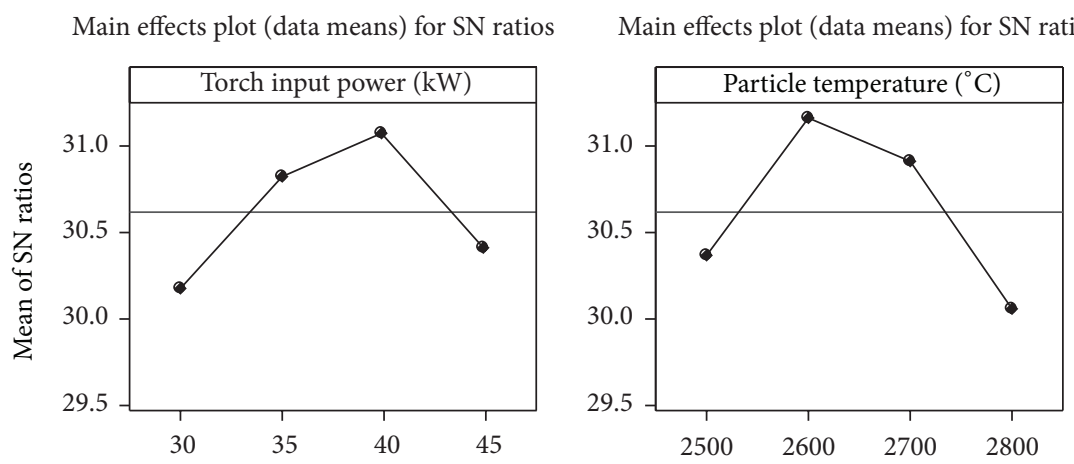

Main effects plot (data means) for SN ratios
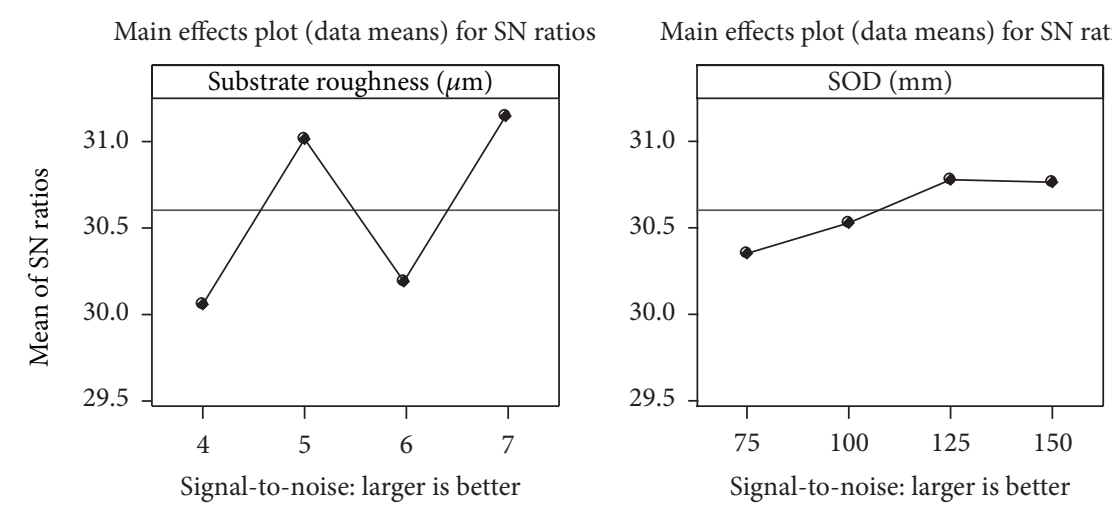

FIGURE 7: Main effect plot for $\mathrm{S} / \mathrm{N}$ ratio of individual control factors.

(1) Successful coating deposition of as-synthesized nanoYSZ powder (by sol gel route) by plasma spraying route is possible on Inconel 718 substrates.

(2) Retention of nanostructure is achieved by monitoring molten state of nanoagglomerates (temperature and velocity) by CCD camera and carefully optimizing process parameters.

(3) From the Taguchi design method, particle velocity is found to be the most significant factor followed 
TABLE 4: Response table for signal-to-noise ratios.

\begin{tabular}{lccccc}
\hline Level & $\mathrm{A}$ & $\mathrm{B}$ & $\mathrm{C}$ & $\mathrm{D}$ & $\mathrm{E}$ \\
\hline 1 & 30.17 & 30.35 & 31.16 & 30.07 & 30.36 \\
2 & 30.82 & 31.16 & 30.85 & 31.03 & 30.54 \\
3 & 31.06 & 30.90 & 30.73 & 30.20 & 30.79 \\
4 & 30.40 & 30.04 & 29.70 & 31.15 & 30.77 \\
Delta & 0.90 & 1.11 & 1.46 & 1.09 & 0.43 \\
Rank & $\mathbf{4}$ & $\mathbf{2}$ & $\mathbf{1}$ & $\mathbf{3}$ & $\mathbf{5}$ \\
\hline
\end{tabular}

by SOD and particle temperature, influencing the adhesion strength of coated sample.

(4) Maximum adhesion of $40.56 \mathrm{MPa}$ is achieved experimentally by optimizing process parameters using Taguchi experimental design.

\section{References}

[1] G. Di Girolamo, C. Blasi, M. Schioppa, and L. Tapfer, "Structure and thermal properties of heat treated plasma sprayed ceriayttria co-stabilized zirconia coatings," Ceramics International, vol. 36, no. 3, pp. 961-968, 2010.

[2] S. Das, S. Datta, D. Basu, and G. C. Das, "Thermal cyclic behavior of glass-ceramic bonded thermal barrier coating on nimonic alloy substrate," Ceramics International, vol. 35, no. 6, pp. 2123-2129, 2009.

[3] X. Chen, Y. Zhao, X. Fan et al., "Thermal cycling failure of new $\mathrm{LaMgAl}{ }_{11} \mathrm{O}_{19} / \mathrm{YSZ}$ double ceramic top coat thermal barrier coating systems," Surface \& Coatings Technology, vol. 205, no. 10, pp. 3293-3300, 2011.

[4] N. Wang, C. Zhou, S. Gong, and H. Xu, "Heat treatment of nanostructured thermal barrier coating," Ceramics International, vol. 33, no. 6, pp. 1075-1081, 2007.

[5] X. Chen, L. Gu, B. Zou, Y. Wang, and X. Cao, "New functionally graded thermal barrier coating system based on $\mathrm{LaMgAl}_{11} \mathrm{O}_{19} / \mathrm{YSZ}$ prepared by air plasma spraying," Surface \& Coatings Technology, vol. 206, no. 8-9, pp. 2265-2274, 2012.

[6] G. Di Girolamo, C. Blasi, L. Pagnotta, and M. Schioppa, "Phase evolution and thermophysical properties of plasma sprayed thick zirconia coatings after annealing," Ceramics International, vol. 36, no. 8, pp. 2273-2280, 2010.

[7] H. D. Steffens, Z. Babiak, and W. Brandl, "Thermal barrier coatings: some aspects of properties design," in Proceedings of the 4th National Thermal Spray Conference: Thermal Spray CoatingsProperties, Processes and Applications (Pennsylvania USA, May 1991), T. F. Bernecki, Ed., pp. 289-294, ASM International, Materials Park, Ohio, USA, 1991.

[8] C. R. C. Lima and R. Da Exaltação Trevisan, "Temperature measurements and adhesion properties of plasma sprayed thermal barrier coatings," Journal of Thermal Spray Technology, vol. 8, no. 2, pp. 323-327, 1999.

[9] M. Tamura, M. Takahashi, J. Ishii, K. Suzuki, M. Sato, and K. Shimomura, "Multilayered thermal barrier coating for landbased gas turbines," Journal of Thermal Spray Technology, vol. 8, no. 1, pp. 68-72, 1999.

[10] A. J. Slifka, B. J. Filla, J. M. Phelps, G. Bancke, and C. C. Berndt, "Thermal conductivity of a zirconia thermal barrier coating," Journal of Thermal Spray Technology, vol. 7, no. 1, pp. 43-46, 1998.
[11] X. Q. Cao, R. Vassen, and D. Stoever, "Ceramic materials for thermal barrier coatings," Journal of the European Ceramic Society, vol. 24, no. 1, pp. 1-10, 2004.

[12] L. Leblanc, "Abrasion and sliding wear of nanostructured ceramic coatings," in Thermal Spray 2003: Advancing the Science \& Applying the Technology, C. Moreau and B. Marple, Eds., pp. 291-299, ASM International, Materials Park, Ohio, USA, 2003.

[13] V. Chawla, B. S. Sidhu, D. Puri, and S. Prakash, "Performance of plasma sprayed nanostructured and conventional coatings," Journal of the Australian Ceramic Society, vol. 44, no. 2, pp. 5662, 2008 .

[14] C. Ding, H. Chen, X. Liu, and Y. Zeng, "Plasma sprayed nanostructured zirconia coatings for wear resistance," in Thermal Spray 2003: Advancing the Science \& Applying the Technology, C. Moreau and B. Marple, Eds., pp. 455-458, ASM International, Materials Park, Ohio, USA, 2003.

[15] M. Gell, E. H. Jordan, Y. H. Sohn, D. Goberman, L. Shaw, and T. D. Xiao, "Development and implementation of plasma sprayed nanostructured ceramic coatings," Surface \& Coatings Technology, vol. 146-147, pp. 48-54, 2001.

[16] H. Chen and C. X. Ding, "Nanostructured zirconia coating prepared by atmospheric plasma spraying," Surface \& Coatings Technology, vol. 150, no. 1, pp. 31-36, 2002.

[17] L. Zhao and E. Lugscheider, "Influence of the spraying processes on the properties of 316L stainless steel coatings," Surface \& Coatings Technology, vol. 162, no. 1, pp. 6-10, 2003.

[18] S. Beauvais, V. Guipont, F. Borit et al., "Process-microstructureproperty relationships in controlled atmosphere plasma spraying of ceramics," Surface \& Coatings Technology, vol. 183, no. 2-3, pp. 204-211, 2004.

[19] B.-Y. Chou and E. Chang, "Microstructural characterization of plasma-sprayed hydroxyapatite- $10 \mathrm{wt} \% \mathrm{ZrO}_{2}$ composite coating on titanium," Biomaterials, vol. 20, no. 19, pp. 1823-1832, 1999.

[20] S. Guessasma, G. Montavon, and C. Coddet, "On the neuronal network concept to describe the thermal spray deposition process: an introduction," in Proceedings of the International Thermal Spray Conference (ITSC '02), E. Lugscheider and C. C. Berndt, Eds., pp. 57-61, ASM International, Materials Park, Ohio, USA.

[21] C. C. Berndt and C. K. Lin, "Measurement of adhesion for thermally sprayed materials," Journal of Adhesion Science and Technology, vol. 7, no. 12, pp. 1235-1264, 1993.

[22] R. E. Juárez, D. G. Lamas, G. E. Lascalea, and N. E. Walsöe de Reca, "Synthesis of nanocrystalline zirconia powders for TZP ceramics by a nitrate-citrate combustion route," Journal of the European Ceramic Society, vol. 20, no. 2, pp. 133-138, 2000.

[23] V. Viswanathan, K. E. Rea, A. Vaidya, and S. Seal, "Role of spray drying of nanoagglomerates in morphology evolution in nanostructured APS coatings," Journal of the American Ceramic Society, vol. 91, no. 2, pp. 379-386, 2008.

[24] J. Vattulainen, E. Hämäläinen, R. Hernberg, P. Vuoristo, and T. Mäntylä, "Novel method for in-flight particle temperature and velocity measurements in plasma spraying using a single CCD camera," Journal of Thermal Spray Technology, vol. 10, no. 1, pp. 94-104, 2001.

[25] C. Pierlot, L. Pawlowski, M. Bigan, and P. Chagnon, "Design of experiments in thermal spraying: a review," Surface \& Coatings Technology, vol. 202, no. 18, pp. 4483-4490, 2008.

[26] W.-C. Lih, S. H. Yang, C. Y. Su, S. C. Huang, I. C. Hsu, and M. S. Leu, "Effects of process parameters on molten particle speed and surface temperature and the properties of $\mathrm{HVOF} \mathrm{CrC} / \mathrm{NiCr}$ 
coatings," Surface \& Coatings Technology, vol. 133-134, pp. 5460, 2000 .

[27] A. C. Leger, M. Vardelle, A. Vardelle et al., "Plasma sprayed zirconia: relationships between particles parameters, splat formation and deposit generation. Part I: impact and solidification," in Thermal Spray: Practical Solutions for Engineering Problems, C. C. Berndt, Ed., pp. 623-629, ASM International, Materials Park, Ohio, USA, 1996.

[28] R. S. Lima and B. R. Marple, "Thermal spray coatings engineered from nanostructured ceramic agglomerated powders for structural, thermal barrier and biomedical applications: a review," Journal of Thermal Spray Technology, vol. 16, no. 1, pp. 40-63, 2007. 

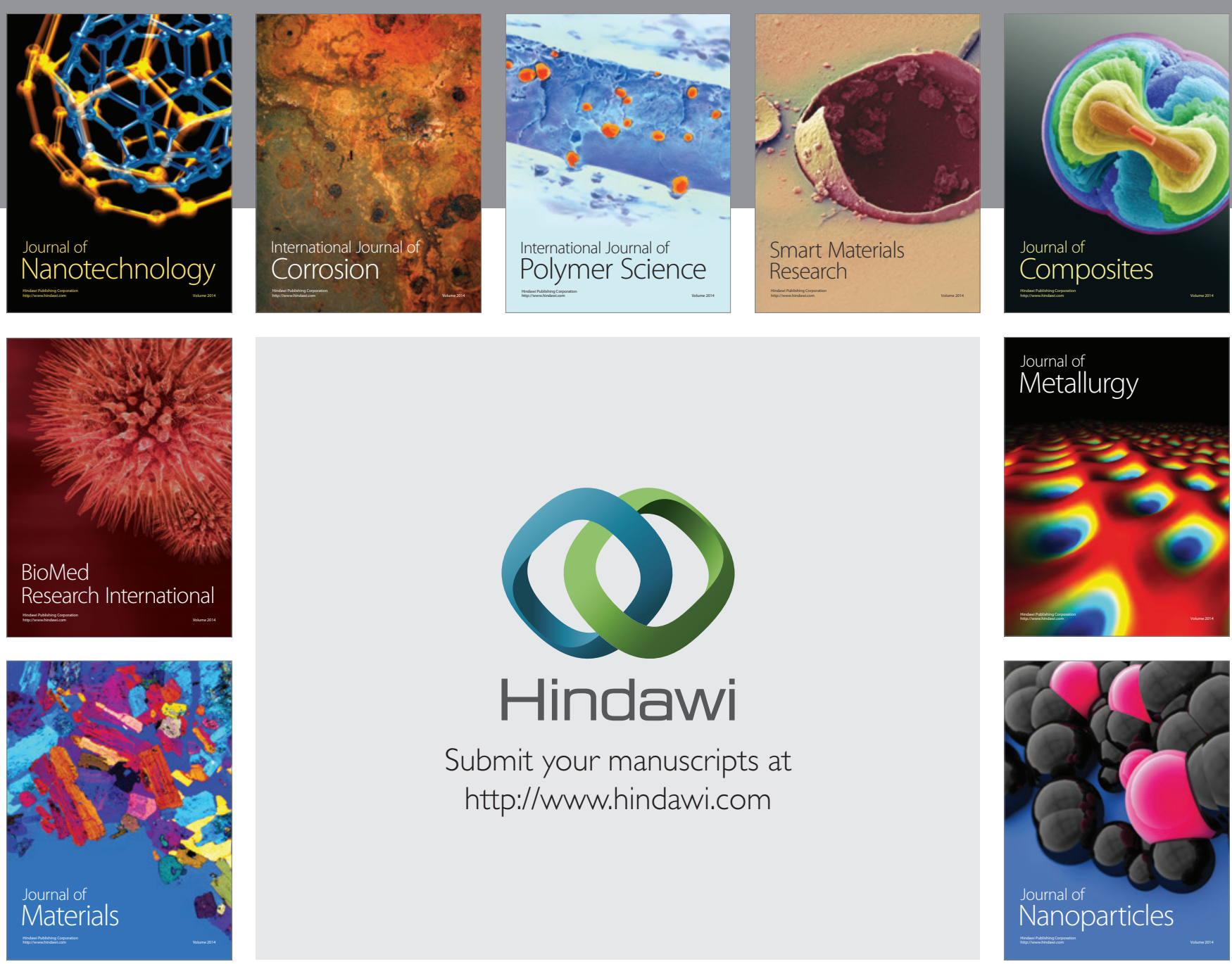

Submit your manuscripts at http://www.hindawi.com
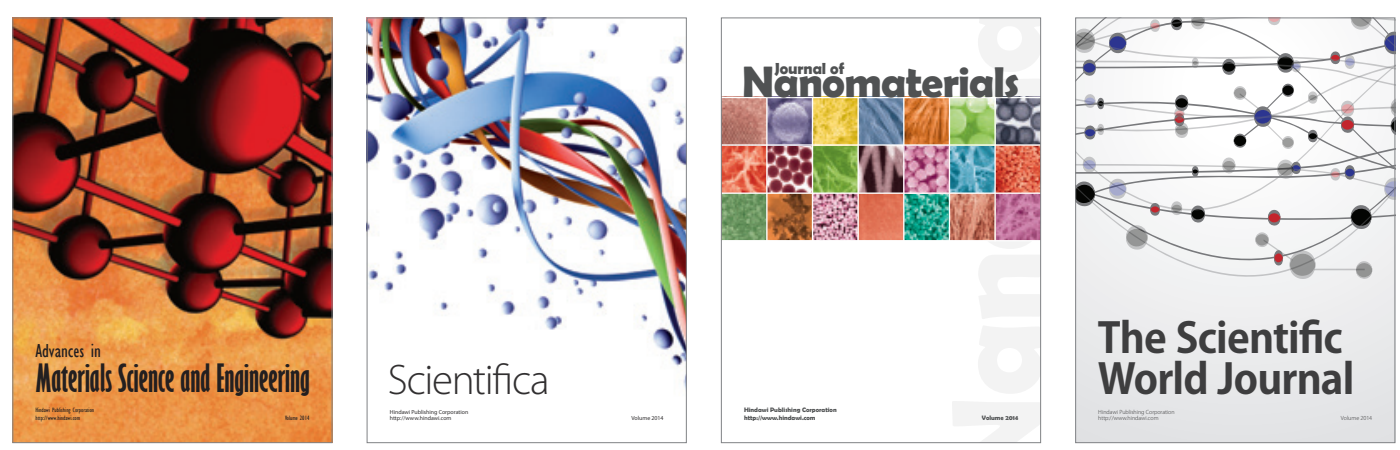

\section{The Scientific World Journal}
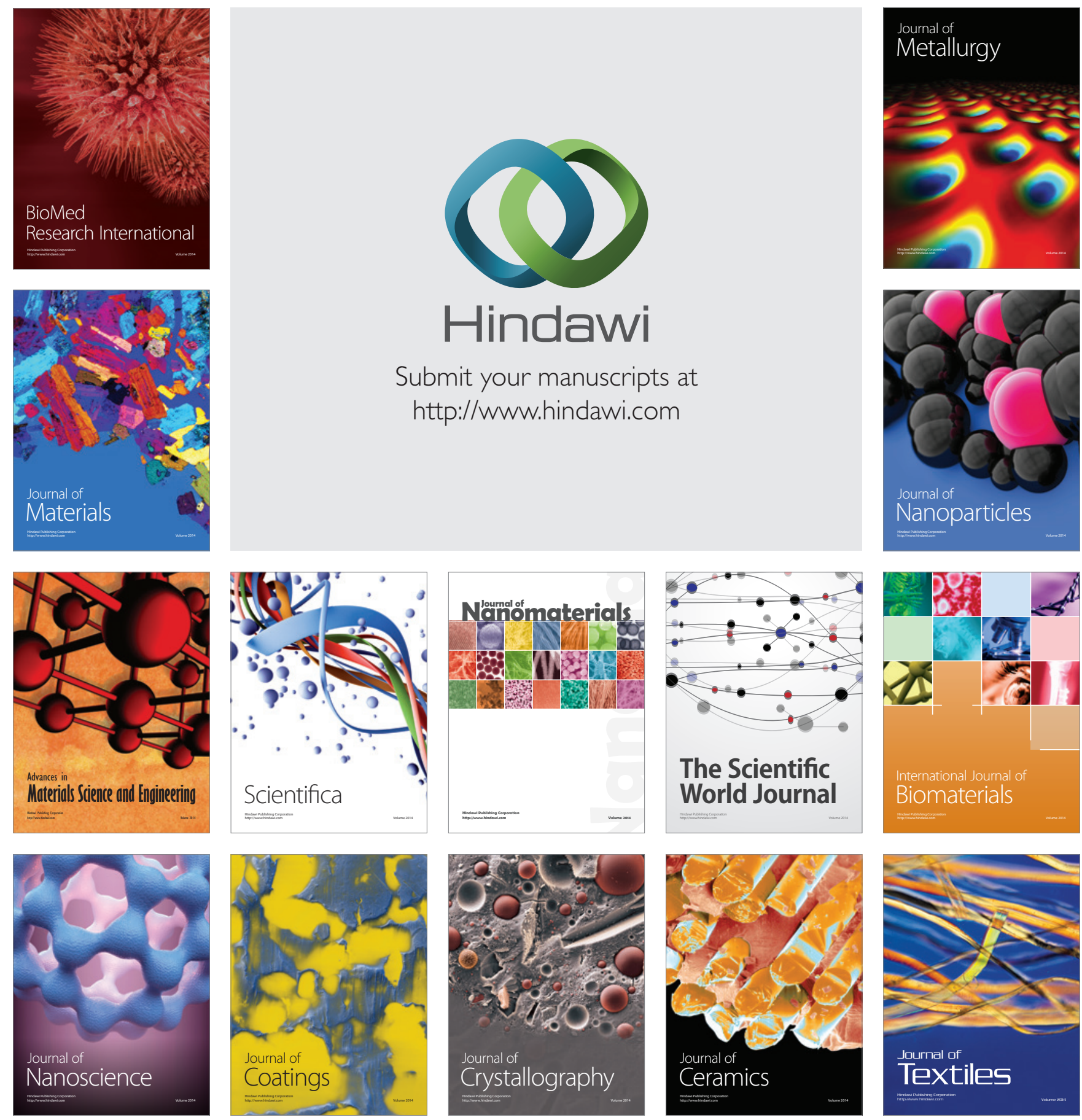